\title{
Porcelain sectional veneers, an ultra-conservative technique for diastema closure (three-dimensional finite element stress analysis)
}

\section{Ultrazachowawcza technika zamykania diastem za pomocą częściowych licówek porcelanowych (analiza naprężenia trójwymiarową metodą elementów skończonych)}

\author{
Rami Shurbaji Mozayek ${ }^{1, A-F}$, Mirza Allafl'A,C,E,F, Suleiman Dayoub ${ }^{2, A, E, F}$ \\ ${ }^{1}$ Department of Fixed Prosthodontics, Faculty of Dentistry, Damascus University, Syria \\ ${ }^{2}$ Department of Periodontology, Faculty of Dentistry, Damascus University, Syria \\ A - research concept and design; $\mathrm{B}$ - collection and/or assembly of data; $\mathrm{C}$ - data analysis and interpretation; \\ $\mathrm{D}$ - writing the article; $\mathrm{E}$ - critical revision of the article; $\mathrm{F}$ - final approval of the article
}

Address for correspondence

Rami Shurbaji Mozayek

E-mail: ramishm88@gmail.com

Funding sources

None declared

Conflict of interest

None declared

Received on January 26, 2019

Reviewed on January 27, 2019

Accepted on February 20, 2019

Published online on May 17, 2019

Cite as

Shurbaji Mozayek R, Allaf M, Dayoub S. Porcelain sectional veneers, an ultra-conservative technique for diastema closure (three-dimensional finite element stress analysis). Dent Med Probl. 2019;56(2):179-183. doi:10.17219/dmp/104602

DOI

$10.17219 / \mathrm{dmp} / 104602$

Copyright

๑ 2019 by Wroclaw Medical University

This is an article distributed under the terms of the

Creative Commons Attribution 3.0 Unported License (CC BY 3.0)

(https://creativecommons.org/licenses/by/3.0/)

\begin{abstract}
Background. Diastema can be closed using conservative and non-conservative techniques. Composite resin wings and ceramic veneers are the most common treatment options if there is no indication for orthodontic treatment. A novel ultra-conservative technique has been introduced to the practice, i.e., porcelain sectional veneers can be fabricated with no or minimum preparation. However, porcelain is known for its poor mechanical properties and the long-term survival of such restorations is questionable.

Objectives. This paper aimed to investigate the mechanical aspects of porcelain sectional veneers by means of the finite element method (FEM).

Material and methods. A three-dimensional (3D) model of porcelain sectional veneers on the upper central incisors with diastema was obtained by the reversed engineering method starting from a cone-beam computed tomography (CBCT) image. A $100 \mathrm{~N}$ occlusal force was applied parallel and $135^{\circ}$ to the longitudinal axis, respectively. For each direction the force was applied once with direct contact and again with no contact with the porcelain sectional veneers. For each of the resulting 4 scenarios, a 3 D finite element analysis was simulated and the maximum equivalent von Mises stress was compared to porcelain flexural strength.

Results. Higher stresses were detected when the force was applied on the porcelain sectional veneers and they were increased dramatically with the inclined force.

Conclusions. Direct occlusal contact has to be avoided when using porcelain sectional veneers and the margin positions must be chosen carefully. The occlusal scheme must be noted carefully before choosing this type of restoration.
\end{abstract}

Key words: finite element, diastema, porcelain sectional veneers, no-prep

Słowa kluczowe: element skończony, diastema, częściowe licówki porcelanowe, licówki no-prep 


\section{Introduction}

The awareness of the importance of dental tissue is spreading among patients nowadays; however, increased esthetics is continuously required. ${ }^{1-3}$

One of the most frequent dilemmas that may be encountered in the dental office is which of the 2 common treatment plans for sound teeth to choose in the case of diastema. The first one is closing the diastema by composite resin; this technique may be more conservative for the tooth structure, but it still does not offer the greatest esthetics and the teeth are susceptible to color change overtime. ${ }^{4-11}$ The second one - ceramic laminate veneers - offers much better esthetics than composite resin, more durability and resistance to color changes, and is considered a minimally invasive technique, which is regarded as an advantage. ${ }^{12-17}$

Now we are looking for techniques which might comprise the best of the above-mentioned approaches. The porcelain sectional veneer has been suggested as an innovative ultra-conservative technique that covers only part of the tooth surface without any preparation to be made and has the esthetic appearance of the ceramic laminate veneer. ${ }^{18-24}$

This paper aimed to study the mechanical aspects of porcelain sectional veneers by means of a three-dimensional (3D) finite element analysis and by comparing the maximum von Mises stress with porcelain flexural strength in order to predict the prognosis of such restorations.

\section{Material and methods}

A 3D model of porcelain sectional veneers on the upper central incisors with diastema was prepared by the reversed engineering method.

A cone-beam computed tomography (CBCT) scan for a 20-year-old patient's maxilla with a diastema between the upper central incisors was obtained. The data set format known as "dicom" was imported into Mimics ${ }^{\circledR}$ v. 17.0 (Materialise Interactive Medical Image Control System; Materialise, Inc., Leuven, Belgium) in order to create separate two-dimensional (2D) masks for each of the following: the bone, periodontal ligaments, pulp, dentine, and enamel (Fig. 1). Then, the masks were converted into 3D geometric models and porcelain sectional veneers were designed digitally with a gradual thickness from $0.1 \mathrm{~mm}$
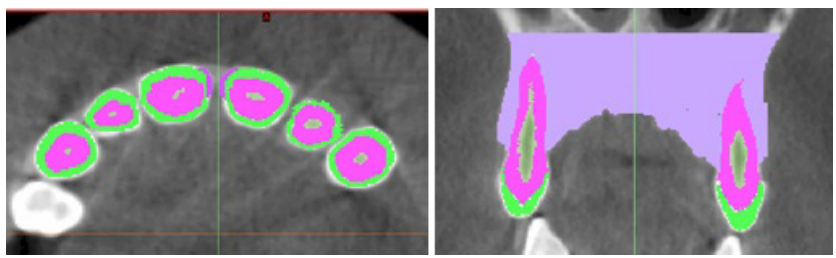

Fig. 1. Masks representing the model tissues at the buccal surface of the tooth to $1 \mathrm{~mm}$ at the contact point mesially. To simplify the model, it was cropped to a block containing the upper incisors and canines (Fig. 2).

The resulting masks were exported in STL format to 3-matic ${ }^{\circledR}$ software v. 9.0 (Materialise, Inc.). The model was smoothed and converted into Non-Uniform Rational Basis Spline (NURBS), then exported as an IGS file to PowerShape 2015 software v. 15.1.4 (Delcam, Birmingham, UK), which was used to convert the NURBS model to a volumetric model, and a parasolid file (X_T format) was obtained.
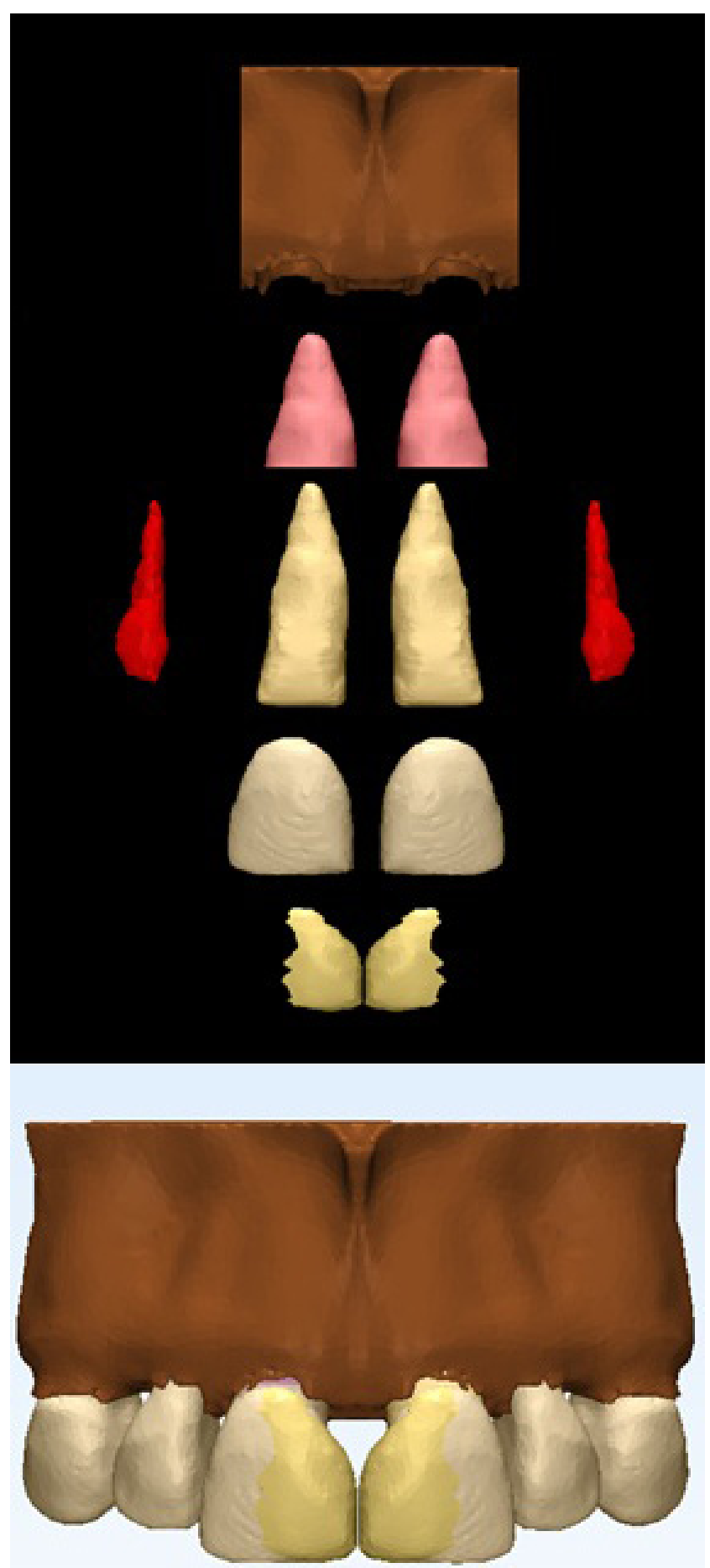

Fig. 2. 3D geometrical model 
After that, the final model was imported into ANSYS ${ }^{\circledR}$ Workbench v. 15 (ANSYS, Inc., Canonsburg, USA), and the following steps were performed:

1. Verification of contact surfaces between different bodies and bonding them together to ensure continuous displacement during loading. The cement layer was simulated by defining bonded contact between the enamel and the porcelain sectional veneers.

2.Defining material properties: bone is an inhomogeneous, anisotropic material, but since it is not possible to accurately represent the non-linear behavior and inhomogeneity of bone, it was considered to be linear, elastic, homogeneous, and isotropic in this study; thus, it can be defined with both Young's modulus of elasticity and Poisson's ratio. Table 1 shows the values for the materials used in this study. ${ }^{25,26}$

Table 1. Material properties of the model components

\begin{tabular}{|l|c|c|c|c|c|c|}
\hline $\begin{array}{l}\text { Materials } \\
\text { properties }\end{array}$ & Bone & $\begin{array}{c}\text { Periodontal } \\
\text { ligament }\end{array}$ & Pulp & Dentine & Enamel & Porcelain \\
\hline $\begin{array}{l}\text { Young's } \\
\text { modulus } \\
{[\mathrm{MPa}]}\end{array}$ & 13,700 & 50 & 2.1 & 18,620 & 84,000 & 82,800 \\
$\begin{array}{l}\text { Poisson's } \\
\text { ratio }\end{array}$ & 0.30 & 0.49 & 0.45 & 0.31 & 0.31 & 0.35 \\
\hline
\end{tabular}

3. Defining boundary conditions: the model was supported from the bottom to allow the bone to bend under load; the occlusal force was represented in 4 cases according to the area of effect and force direction $^{27-29}$ :

(a-1) the force is applied on the tooth structure only (the palatal surface) and not on the porcelain sectional veneer, and the force direction is parallel to the tooth longitudinal axis $\left(0^{\circ}\right)$ (Fig. 3);

(a-2) the force is applied on the tooth structure only (the palatal surface) and not on the porcelain sectional veneer, and the force direction is $135^{\circ}$ to the tooth longitudinal axis palatally (Fig. 4);

(b-1) the force is applied on the tooth structure (the palatal surface) and extended to the porcelain sectional veneer, and the force direction is parallel to the tooth longitudinal axis $\left(0^{\circ}\right)$ (Fig. 5);

(b-2) the force is applied on the tooth structure (the palatal surface) and extended to the porcelain sectional veneer, and the force direction is $135^{\circ}$ to the tooth longitudinal axis palatally (Fig. 6).

Force magnitude was $100 \mathrm{~N}$ in each case. After that, the 4 case models were meshed into 62,595 tetrahedral elements, 12,0485 nodes and processed, and the maximum equivalent von Mises stress in the porcelain sectional veneers was obtained and compared to porcelain flexural strength.

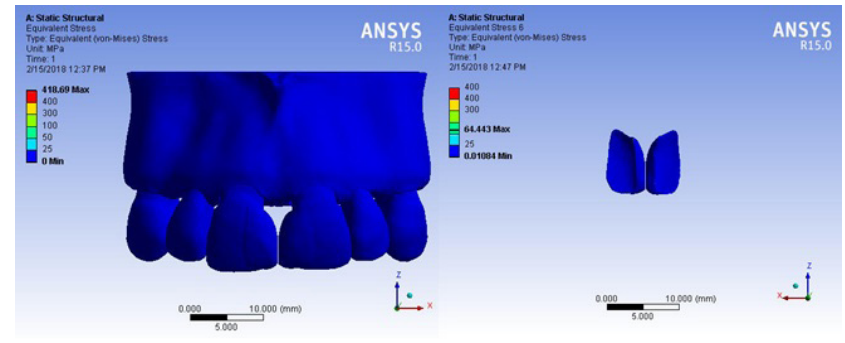

Fig. 3. Scenario a-1: The force is applied on the tooth structure only and not on the porcelain sectional veneer, and the force direction is parallel to the tooth longitudinal axis $\left(0^{\circ}\right)$

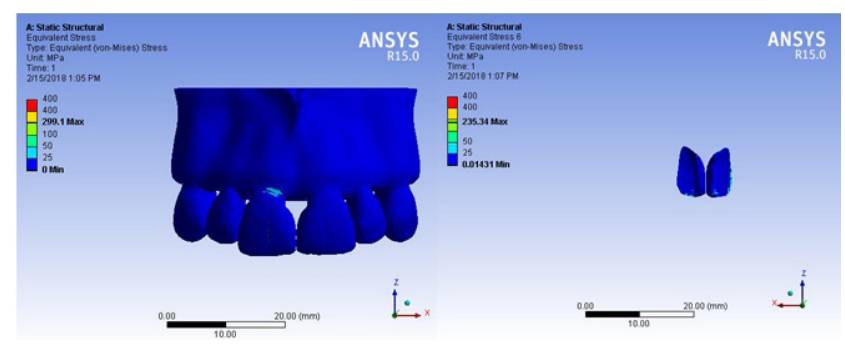

Fig. 4. Scenario a-2: The force is applied on the tooth structure only and not on the porcelain sectional veneer, and the force direction is $135^{\circ}$ to the tooth longitudinal axis palatally

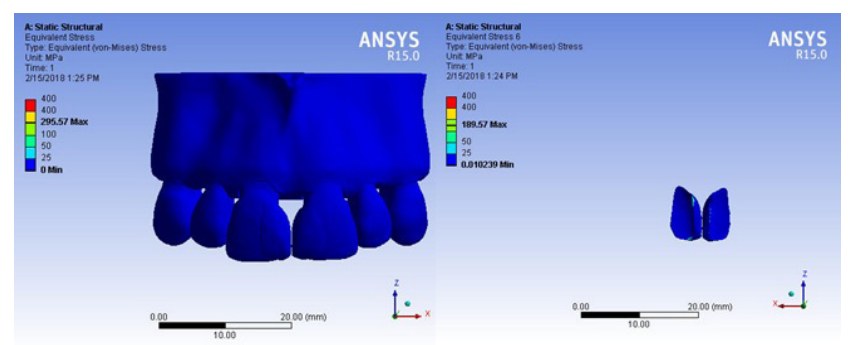

Fig. 5. Scenario b-1: The force is applied on the tooth structure and on the porcelain sectional veneer, and the force direction is parallel to the tooth longitudinal axis $\left(0^{\circ}\right)$

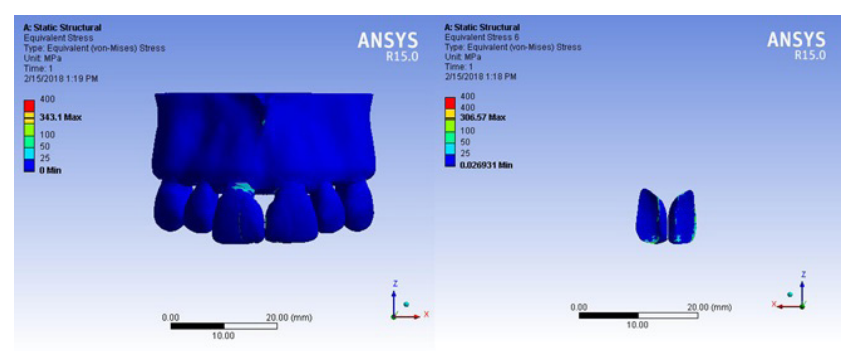

Fig. 6. Scenario b-2: The force is applied on the tooth structure and on the porcelain sectional veneer, and the force direction is $135^{\circ}$ to the tooth longitudinal axis palatally

\section{Statistical analysis}

Since no repetitive tests were executed in this study $(n=1)$, comparison of the results of each tested model was made by descriptive statistics. 


\section{Results}

The maximum equivalent von Mises stress of the porcelain sectional veneers for each case is shown in Table 2.

Higher stresses were detected when the force was applied on the porcelain sectional veneers.

Also, the inclined force caused more stress regardless of the force point of effect.

Stress distribution was similar in all cases; the thin margins of porcelain sectional veneers, especially at the buccal aspect, suffered the maximum stress. There was another concentration point at the interior angle opposite to the incisal angle of the tooth.

Table 2. Von Mises stress for each case

\begin{tabular}{|c|c|c|}
\multirow{2}{*}{ Area of effect } & \multicolumn{2}{|c|}{$\begin{array}{c}\text { Force direction compared } \\
\text { to tooth longitudinal axis [MPa] }\end{array}$} \\
\cline { 2 - 3 } & $0^{\circ}$ & $135^{\circ}$ \\
\hline Tooth structure only & 64.44 & 235.34 \\
Tooth and porcelain & 189.57 & 306.57 \\
\hline
\end{tabular}

\section{Discussion}

Many treatment plans have been suggested for diastema closure, e.g., orthodontic treatment, laminate veneers, crowning, and composite restorations. ${ }^{30}$ Still, there may be a gap between achieving high esthetics and conserving dental tissues.

One of the novel approaches suggested for diastema closure is using porcelain sectional veneers (also called partial veneers), ${ }^{18-24}$ which provide ceramic esthetics and do not require dental tissue preparation.

Porcelain is known to have excellent esthetics but low strength, ${ }^{31}$ and sectional veneers are characterized by very thin margins, so it is legitimate to question their strength and durability. This paper is concerned with studying the mechanical aspects of porcelain sectional veneers in 4 different scenarios related to force direction and force point of effect using the finite element method (FEM).

The finite element method is a virtual numerical analysis that can bring acceptable and reliable results if the conditions of simulations are as accurate as possible. On the other hand, FEM is a subjective method, which may provide different outcomes if different researchers-programers introduce their own vision of the loading conditions, material properties and boundary conditions. Therefore, FEM cannot be a complete substitute for clinical studies, but it is more like a guide, especially in cases where the studies are difficult to conduct or ethically unacceptable.

Durability of the restorations under loading conditions can be foreseen by comparing the maximum value of equivalent von Mises stress of the material to its flexural strength.
Porcelain flexural strength may vary depending on the brand and manufacturer, but generally it is accepted to be 80-110 $\mathrm{MPa}^{32,33}$ Based on the results obtained in the present study, it can be noted that if the porcelain sectional veneer is out of occlusion and the occlusal force is parallel to the longitudinal axis of the tooth, the equivalent von Mises stress is lower than the flexural strength and restoration survival can be expected. On the other hand, the occlusal forces acting directly on the restoration may lead to stresses which cannot be tolerated and a fracture will probably occur.

Angulated force increased the stresses dramatically, even if no direct contact to the restoration was found; the occlusal scheme of the patient could have a great influence on restoration survival, especially anterior excursions, which induce oblique occlusal forces. Parafunctional habits may also lead to such forces and have the same or even greater effect on the restoration.

By observing the stress distribution, it can be noted that the thin margins of the sectional veneer exhibit the maximum stress values, and the margins must be checked regularly to avoid any complications and to ensure good marginal integrity; it can be expected that having a strong bite might cause the chipping of the buccal porcelain margins, which may affect the esthetics dramatically. Moreover, the interior angle opposite to the incisal angle must be taken care of by providing adequate thickness and rounding the angle, which can reduce stress concentration in this area.

Porcelain sectional veneers have mechanical limitations and thus good clinical judgment must be made according to the patient's needs, occlusion and bite force. However, further clinical studies have to be conducted, and clinical evidence and long-term success must be verified.

\section{Conclusions}

Within the limitations of this numerical analysis study, it can be concluded that porcelain sectional veneers are an esthetic option with low mechanical properties and as such must not have a direct occlusal contact. The oblique forces, which may be induced by anterior excursions or parafunctional habits for instance, threaten the survival of the restorations, even if they are not applied directly on the veneers, and may lead to failure. This feature distinguishes porcelain sectional veneers from ordinary porcelain full laminate veneers. The thin margins of porcelain sectional veneers are considered to be a weak point, and they must be positioned carefully and checked regularly. Attention must be paid due to strong occlusal forces, which may cause buccal margin chipping rather than fracture or debonding.

\section{ORCID iDs}

Rami Shurbaji Mozayek (D) https://orcid.org/0000-0002-8399-4025

Mirza Allaf (D) https://orcid.org/0000-0003-1974-1995

Suleiman Dayoub (D) https://orcid.org/0000-0003-0671-9473 


\section{References}

1. Archangelo $C M$, Romanini JC, Archangelo KC, Hoshino IAE, Anchieta RB Minimally invasive ceramic restorations: A step-by-step clinical approach. Compend Contin Educ Dent. 2018;39(4):e4-e8.

2. Kamble VD, Parkhedkar RD. Esthetic rehabilitation of discolored anterior teeth with porcelain veneers. Contemp Clin Dent. 2013;4(1):124-126.

3. Stewart H. Minimally invasive bio-rejuvenation dentistry: A conservative approach to full-mouth rehabilitation. Dent Today. 2017;36(5):94-98.

4. Lempel E, Lovász BV, Meszarics $R$, Jeges $S$, Tóth A, Szalma J. Direct resin composite restorations for fractured maxillary teeth and diastema closure: A 7 years retrospective evaluation of survival and influencing factors. Dent Mater. 2017;33(4):467-476.

5. Katsarou T, Antoniadou M, Papazoglou E. Effectiveness of optical illusions applied on a single composite resin veneer for the diastema closure of maxillary central incisors. Int J Esthet Dent. 2017;12(1):42-59.

6. Goyal A, Nikhil V, Singh R. Diastema closure in anterior teeth using a posterior matrix. Case Rep Dent. 2016;2016:2538526.

7. Korkut B, Yanikoglu F, Tagtekin D. Direct midline diastema closure with composite layering technique: A one-year follow-up. Case Rep Dent. 2016;2016:1-5.

8. Barros de Campos PR, Maia RR, Rodrigues de Menezes L, Barbosa IF, Carneiro da Cunha A, da Silveira Pereira GD. Rubber dam isolation - key to success in diastema closure technique with direct composite resin. Int J Esthet Dent. 2015;10(4):564-574.

9. Prabhu R, Bhaskaran S, Geetha Prabhu KR, Eswaran MA, Phanikrishna G, Deepthi $B$. Clinical evaluation of direct composite restoration done for midline diastema closure - long-term study. J Pharm Bioallied Sci. 2015:7(Suppl 2):S559-S562.

10. Demirci M, Tuncer S, Öztaş E, Tekçe N, Uysal Ö. A 4-year clinical evaluation of direct composite build-ups for space closure after orthodontic treatment. Clin Oral Investig. 2015;19(9):2187-2199.

11. Soo TC. Median diastema closure. Dent Update. 1985;12(2):121-122, 124,126-127.

12. Prevedello GC, Vieira M, Furuse AY, Correr GM, Gonzaga CC. Esthetic rehabilitation of anterior discolored teeth with lithium disilicate allceramic restorations. Gen Dent. 2012;60(4):e274-e278.

13. Calamia V, Pantzis A. Simple case treatment planning: Diastema closure. Dent Clin North Am. 2015;59(3):655-664.

14. Oquendo A, Brea L, David S. Diastema: Correction of excessive spaces in the esthetic zone. Dent Clin North Am. 2011;55(2):265-281.

15. Nakamura T, Nakamura T, Ohyama T, Wakabayashi K. Ceramic restorations of anterior teeth without proximal reduction: A case report. Quintessence Int. 2003;34(10):752-755.

16. Rosenthal L. Diastema closure utilizing porcelain veneers - simple and advanced. Dent Econ. 1994;84(7):63-64.

17. Chua EK, Sim C, Yuen KW. Closure of median diastema - a conservative approach. Restorative Dent. 1991;7(2):32-33,37.

18. Magne $P$, Hanna J, Magne M. The case for moderate "guided prep" indirect porcelain veneers in the anterior dentition. The pendulum of porcelain veneer preparations: From almost no-prep to overprep to no-prep. Eur J Esthet Dent. 2013;8(3):376-388.

19. Farias-Neto A, Gomes EM, Sánchez-Ayala A, Sánchez-Ayala A, Vilanova LS. Esthetic rehabilitation of the smile with no-prep porcelain laminates and partial veneers. Case Rep Dent. 2015;2015:452765.

20. Gresnigt M, Ozcan M. Esthetic rehabilitation of anterior teeth with porcelain laminates and sectional veneers. J Can Dent Assoc. 2011;77:b143.

21. Okida RC, Filho AJ, Barao VA, Dos Santos DM, Goiato MC. The use of fragments of thin veneers as a restorative therapy for anterior teeth disharmony: A case report with 3 years of follow-up. J Contemp Dent Pract. 2012;13(3):416-420.

22. Signore A, Kaitsas V, Tonoli A, Angiero F, Silvestrini-Biavati A, Benedicenti $S$. Sectional porcelain veneers for a maxillary midline diastema closure: A case report. Quintessence Int. 2013;44(3):201-206.

23. Vadini M, D'Amario M, De Angelis F, Falco A, D'Arcangelo C. No-prep rehabilitation of fractured maxillary incisors with partial veneers. J Esthet Restor Dent. 2016;28(6):351-358.

24. McLaren EA, LeSage B. Feldspathic veneers: What are their indications? Compend Contin Educ Dent. 2011;32(3):44-49.
25. Abunassar J. Post-Core restorations stresses by finite element analysis and mechanical tests. PhD Thesis, Damascus University, Syria, 2000.

26. Rees JS, Jacobsen PH. Elastic modulus of the periodontal ligament. Biomaterials. 1997;18(14):995-999.

27. Yıkılgan I, Bala O. How can stress be controlled in endodontically treated teeth? A 3D finite element analysis. ScientificWorldJournal. 2013;2013:426134.

28. Park YS, Kwon HB. Three-dimensional finite element analysis of implant-supported crown in fibula bone model. J Adv Prosthodont. 2013;5(3):326-332

29. Ukon S, Moroi $H$, Okimoto K, et al. Influence of different elastic moduli of dowel and core on stress distribution in root. Dent Mat J. 2000;19(1):50-64.

30. Gkantidis N, Psomiadis S, Topouzelis N. Teeth spacing: Etiology and treatment. Hel Orth Rev. 2007;10(2):75-92.

31. Alghazzawi TF, Lemons J, Liu PR, Essig ME, Janowski GM. The failure load of CAD/CAM generated zirconia and glass-ceramic laminate veneers with different preparation designs. J Prosthet Dent. 2012;108(6):386-393.

32. Guruprasada P, Rivankar N, Dhiman RK, Viswambaran M. Evaluation of the effect of surface preparation using phosphoric acid and luting cement on the flexural strength of porcelain laminate veneering material. Med J Armed Forces India. 2015;71(Suppl 2):S299-S305.

33. Venturini AB, Prochnow C, May LG, Bottino MC, Felipe Valandro L. Influence of hydrofluoric acid concentration on the flexural strength of a feldspathic ceramic. J Mech Behav Biomed Mater. 2015;48:241-248. 